\title{
Geociências
}

\section{Fosfatização de solos e evolução da paisagem no arquipélago de Abrolhos, BA}

\author{
Soil phosphatization and landscape evolution at the \\ Abrolhos archipelago, BA
}

\section{Carlos Ernesto Gonçalves Reynaud Schaefer \\ Eng. Agrônomo, PhD. Soil Science Professor Associado do Departamento de Solos Universidade Federal de Viçosa E-mail: carlos.schaefer@ufv.br}

Felipe Nogueira Bello Simas

Eng. Agrônomo, Doutorando em Solos e Nutrição de Plantas Bolsista Pós-Doutorado - CNPq Departamento de Solos Universidade Federal de Viçosa E-mail:fsimass@yahoo.com.br

\section{Miriam Abreu Albuquerque \\ Eng. Agrônoma, PhD. Soil Science Bolsista Pós-Doutorado - Petrobras Departamento de Solos Universidade Federal de Viçosa E-mail: malbuquerque@yahoo.com.br}

\section{Eliana de Souza}

Geógrafa, Doutoranda em Solos e Nutrição de Plantas

Departamento de Solos Universidade Federal de Viçosa E-mail: elianadsouza@yahoo.com.br

\section{Katia Karoline Delpupo \\ Geógrafa, Mestranda em Solos e Nutrição de Plantas Departamento de Solos Universidade Federal de Viçosa E-mail:karoldelpupo@yahoo.com.br}

\section{Resumo}

A atividade da avifauna nos ecossistemas terrestres imprime profundas alterações químicas e mineralógicas nos substratos minerais. O objetivo do presente trabalho é investigar os impactos da atividade da avifauna na evolução da paisagem do arquipélago de Abrolhos através do estudo da distribuição espacial dos solos e suas características químicas, com ênfase na fosfatização. Foram estudados dez perfis de solos representativos das principais unidades de paisagem do arquipélago. Com base em observação de campo e interpretação de carta náutica da Marinha do Brasil (n. 1311), em escala 1:100.000, foi produzido o mapa de solos das ilhas. A presença generalizada de solos fortemente ornitogênicos, em áreas sem nidificação atual ou com fraca nidificação, indica uma ocupação pretérita por aves bem mais ampla que a atual. Alguns solos estudados em Abrolhos são de difícil classificação e refletem influência marcante da avifauna, atual ou pretérita.

Palavras-chave: Avifauna, ecossistemas terrestres, ilhas, ornitogênico, solos submersos.

\section{Abstract}

The activity of the avifauna on terrestrial ecosystems results in the intense chemical and mineralogical alteration of mineral substrates. The objective of the present work is to investigate the impact of the avifauna on landscape evolution at the Abrolhos Archipelago, based on soils chemical characteristics and spatial distribution. A total of 10 soil profiles are described and analyzed, representing the main landscape units present in the Archipelago. Based on careful field observation and interpretation made on the existing nautical map (n.1311), produced by the Brazilian Navy (scale 1:100.000), detailed soil maps were produced. The widespread occurrence of strongly ornithogenic soils in areas without current nesting activity indicates a much broader occupation by birds in the past. Some of the studied soils are of difficult classification, and reflect the marked influence of present-day and past avifauna activity.

Keywords: Avifauna, terrestrial ecosystems, islands, ornithogenic, submersed soils. 


\section{Introdução}

A atividade da avifauna em ecossistemas terrestres imprime profundas alterações químicas e mineralógicas nos substratos minerais. Estudos recentes evidenciam a formação de solos ricos em minerais de fosfato em ilhas oceânicas tropicais (Oliveira, 2008) e antárticas (Simas et al., 2007; Schaefer et al., 2008), em decorrência da atividade de aves. A eutrofização promovida pelo guano favorece o desenvolvimento de solos com altos teores de carbono orgânico, resultando em paisagens distintas das áreas não fosfatizadas adjacentes (Tatur et al., 1997; Simas et al., 2007).

Melfi e Flicoteaux (2000) descreveram, em detalhe, a formação de crostas fosfáticas no arquipélago de Abrolhos. Foram identificados dois estágios de transformações químicas das rochas basálticas. O primeiro refere-se ao intemperismo em clima úmido, levando à formação de saprolito argiloferruginoso. Posteriormente, condições mais secas teriam permitido a expansão dos ninhais e acúmulo de guano, levando à fosfatização do saprolito e dos afloramentos de basalto.

Até o presente, inexistem estudos sobre a natureza química e a distribuição dos solos no arquipélago. Há, apenas, uma descrição geral contida no Plano de Manejo do Parque Nacional Marinho (PARNAM) dos Abrolhos (Brasil, 1991). Estudos pedológicos, em escala adequada, fornecem informações fundamentais para o manejo, visando à recuperação e à conservação ambiental. O objetivo do presente trabalho é investigar os impactos da atividade da avifauna na evolução da paisagem do arquipélago de Abrolhos com base na distribuição espacial e nas características químicas dos diferentes tipos de solos que ocorrem nessas ilhas.

\section{Material e métodos 2.1 Áreas de estudo}

O Banco de Abrolhos é o maior alargamento da plataforma continental brasileira, constituído pelo desenvolvimento de bancos de corais e rochas sedimentares terrígenas sobre um substrato vulcânico basáltico do Cretáceo, com até $250 \mathrm{~km}$ de extensão mar adentro (Schaefer et al., 2006). O arquipélago de Abrolhos compreende quatro ilhas (Santa Bárbara, Redonda, Siriba e Sueste) dispostas em forma de semicírculo e, ao norte, uma ilhota denominada Guarita (Figura 1). As ilhas estão distantes cerca de $65 \mathrm{~km}$ da costa, representando saliências descontínuas de um relevo colinoso outrora mais amplo. A precipitação anual média é próxima de $720 \mathrm{~mm}$, concentrados de maio a agosto. Durante os meses mais secos, a precipitação gira em torno de $60 \mathrm{~mm}$ mensais, enquanto no período chuvoso pode chegar a 120 mm mensais (Kemenes, 2003). A temperatura média fica em torno de $27^{\circ} \mathrm{C}$, com mínimas próximas à $10^{\circ} \mathrm{C}$ em julho e máxima de $42^{\circ} \mathrm{C}$ em janeiro e fevereiro (Kemenes, 2003).

\subsection{Caracterização e mapeamento dos solos}

Foram descritas as paisagens das ilhas que compõem o arquipélago e coletadas 29 amostras representando horizontes pedogenéticos de 10 perfis de solo (Tabela 1). Coletaram-se, ainda, uma amostra de areia carbonática nas praias atuais da ilha Santa Bárbara e duas amostras de guano de aves, em Santa Bárbara e Siriba. Os solos foram descritos conforme Lemos e Santos (2005) e classificados segundo o Sistema Brasileiro de Classificação de Solos (SisBCS) (EMBRAPA, 2006). As amostras foram secas ao ar e passadas em peneira de 2 mm e submetida à análises químicas de rotina (EMBRAPA, 1997). A fração <2mm das areias de praia foi triturada em almofariz de ágata e montada em lâmina escavada, sendo submetidas a difração de raios X, em aparelho Rigaku, operando com tensão de $40 \mathrm{kV}$, corrente de $20 \mathrm{~mA}$, a uma velocidade de registro de $10 \mathrm{~mm} \mathrm{~min}^{-1}$. A amplitude da varredura foi de 2 a $60^{\circ}(2 \theta)$, utilizando-se radiação CuK $\alpha$ monocromada. Os difratogramas foram interpretados conforme Brindley e Brown (1980).

O mapeamento dos solos foi realizado a partir da Carta Náutica n ${ }^{\circ} 311$ da Marinha do Brasil, em escala 1:100.000, utilizando-se ferramentas de geoprocessamento e o software ArcGis $9.3^{\circledR}$. Com base nas características dos perfis e na observação da relação solo - relevo, foram delimitadas as unidades que compõem o mapa de solos. As correlações feitas por Demas e Rabenhorst (2001) entre sedimentos de águas rasas e a teoria clássicas de formação do solo (Jenny, 1941) deram origem ao conceito de solos

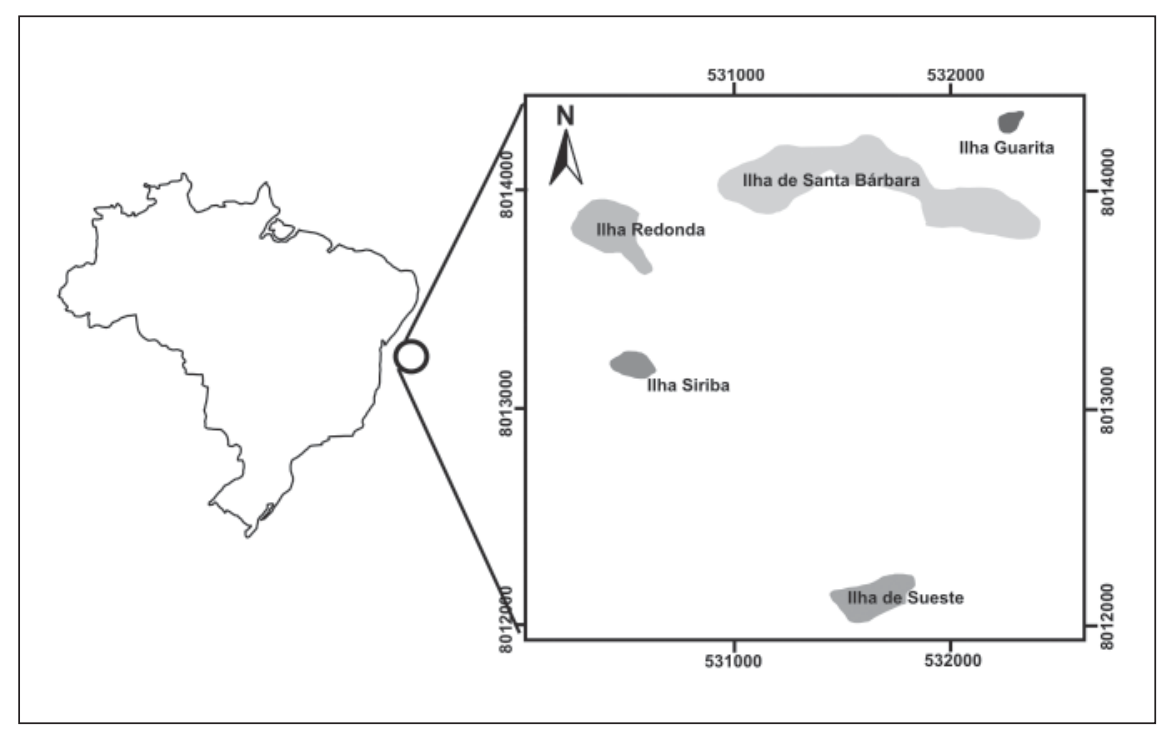

Figura 1 - Localização do arquipélago de Abrolhos. 
Carlos Ernesto Gonçalves Reynaud Schaefer et al.

Tabela 1 - Características gerais dos perfis de solo amostrados no Arquipélago de Abrolhos.

\begin{tabular}{|c|c|c|c|c|}
\hline Perfil & Classificação & Localização & $\begin{array}{l}\text { Posição } \\
\text { geográfica } \\
\text { (UTM) }\end{array}$ & Características gerais \\
\hline 1 & $\begin{array}{l}\text { Neossolo } \\
\text { regolítico eutro- } \\
\text { úmbrico } \\
\text { ornitogênico - } \\
\text { RReh }\end{array}$ & Ilha Redonda & $\begin{array}{l}0530808 \mathrm{E} \\
8013543 \mathrm{~N}\end{array}$ & $\begin{array}{l}\text { Terraço marinho, cerca de } 4 \text { metros acima do nível do mar, } \\
\text { formado em antiga praia de areia carbonática conchífera e algal; } \\
\text { vegetação local de Ipomea/gramíneas rasteiras e alguns } \\
\text { coqueiros. Solo raso, com } 50 \mathrm{~cm} \text { de profundidade. }\end{array}$ \\
\hline 2 & $\begin{array}{l}\text { Neossolo } \\
\text { litólico hístico } \\
\text { ornitogênico - } \\
\text { RLi }\end{array}$ & Ilha Redonda & $\begin{array}{l}0530727 \mathrm{E} \\
8013672 \mathrm{~N}\end{array}$ & $\begin{array}{l}\text { Porção mais elevada da ilha, cerca de } 35 \text { metros acima do nível do } \\
\text { mar. Presença de Ciperáceas gigantes, do tipo Cyperus sp., } \\
\text { formando touceiras compactas e acúmulo de material orgânico } \\
\text { fíbrico em superfície; Solo raso, com } 35 \mathrm{~cm} \text { de profundidade, } \\
\text { formado a partir de basalto, com crosta fosfática na superfície, } \\
\text { indicando antiga fosfatização, hoje extinta. }\end{array}$ \\
\hline 3 & $\begin{array}{l}\text { Neossolo } \\
\text { litólico hístico } \\
\text { ornitogênico - } \\
\text { Rli }\end{array}$ & Ilha Redonda & $\begin{array}{l}0530628 \mathrm{E} \\
8013718 \mathrm{~N}\end{array}$ & $\begin{array}{l}\text { Face norte da ilha, cerca de } 30 \text { metros acima do nível do mar. } \\
\text { Ninhal de fragatas, formando ampla zona de fosfatização, em } \\
\text { terraço marinho e rampa. Solo muito raso, com } 25 \mathrm{~cm} \text { de } \\
\text { profundidade. Acúmulo de guano na superfície e fraturas das } \\
\text { rochas. }\end{array}$ \\
\hline 5 & $\begin{array}{l}\text { Cambissolo } \\
\text { húmico Tb } \\
\text { distrófico } \\
\text { ornitogênico - } \\
\text { CHd }\end{array}$ & $\begin{array}{l}\text { Ilha de Santa } \\
\text { Bárbara }\end{array}$ & $\begin{array}{l}0531821 \mathrm{E} \\
8013890 \mathrm{~N}\end{array}$ & $\begin{array}{l}\text { Terço superior de tálus na face sul da ilha, cerca de } 27 \text { metros } \\
\text { acima do nível do mar. Solo muito profundo, com mais de } 120 \mathrm{~cm} \text {, } \\
\text { sobre saprolito de rocha vulcânica com crosta fosfática em } \\
\text { superfície. Área com maior desenvolvimento de vegetação em } \\
\text { toda a ilha. }\end{array}$ \\
\hline 6 & $\begin{array}{l}\text { Neossolo } \\
\text { litólico húmico } \\
\text { ornitogênico - } \\
\text { RLh }\end{array}$ & $\begin{array}{l}\text { Ilha de Santa } \\
\text { Bárbara }\end{array}$ & $\begin{array}{l}0531448 \mathrm{E} \\
8013848 \mathrm{~N}\end{array}$ & $\begin{array}{c}\text { Solo raso, no topo da llha de Santa Bárbara, próxima ao mirante, } \\
\text { cerca de } 45 \text { metros acima do nível do mar. Ninhal de Atobás em } \\
\text { fase de recuperação de população, formando extensa zona de } \\
\text { fosfatização, que cobre quase toda a zona oeste da ilha; } \\
\text { vegetação rala e pedoclima seco. }\end{array}$ \\
\hline 7 & $\begin{array}{l}\text { Neossolo } \\
\text { litólico húmico } \\
\text { ornitogênico - } \\
\text { RLh }\end{array}$ & Illha Siriba & $\begin{array}{l}0530692 \mathrm{E} \\
8013005 \mathrm{~N}\end{array}$ & $\begin{array}{l}\text { Solo fosfatizado, cerca de } 43 \text { m acima do nivel do mar, com } \\
\text { estrutura granular; vegetação herbácea, parte graminosa. }\end{array}$ \\
\hline 8 & $\begin{array}{l}\text { Organossolo } \\
\text { háplico sáprico } \\
\text { ornitogênico - } \\
\text { OXs }\end{array}$ & Ilha Sueste & $\begin{array}{l}0531722 \mathrm{E} \\
8011953 \mathrm{~N}\end{array}$ & $\begin{array}{l}\text { Terço inferior de encosta a } 18 \text { metros acima do nível do mar; ninho } \\
\text { abandonado de Atobás, solo fosfatizado. Presença de minhocas e } \\
\text { artrópodes de solo. }\end{array}$ \\
\hline 9 & $\begin{array}{l}\text { Chernossolo } \\
\text { ebânico lítico } \\
\text { ornitogênico - } \\
\text { MEK }\end{array}$ & Ilha Sueste & $\begin{array}{l}0531736 \mathrm{E} \\
8011848 \mathrm{~N}\end{array}$ & $\begin{array}{l}\text { Terço superior de encosta, cerca de } 11 \text { metros acima do nível do } \\
\text { mar, face sul, fora dos ninhais de Atobás, rocha profundamente } \\
\text { fosfatizada, menos encrostada que as demais ilhas, com } \\
\text { serapilheira, presença de formigas no solo. }\end{array}$ \\
\hline 10 & $\begin{array}{l}\text { Cambissolo } \\
\text { húmico Tb epi- } \\
\text { eutrófico } \\
\text { ornitogênico - } \\
\text { CHd }\end{array}$ & Ilha Sueste & $\begin{array}{l}0531872 \mathrm{E} \\
8011905 \mathrm{~N}\end{array}$ & $\begin{array}{c}\text { Topo mais elevado e plano da ilha, cerca de } 23 \text { metros de altitude. } \\
\text { Solo fosfatizado; alta diversidade biológica (formigas, larvas de } \\
\text { coleópteros, grilos, baratinhas, aranhas caranguejeiras). }\end{array}$ \\
\hline
\end{tabular}


submersos. Foram usadas as cartas náuticas e observações de campo para separação desse tipo de solo pouco usual em estudos pedológicos clássicos.

\section{Resultados}

O mapa de solos do arquipélago de Abrolhos (Figura 2) possui 15 unidades de mapeamento, a saber:

AFLORAMENTO DE ROCHA(AR) - Representa áreas onde ocorrem afloramentos e conglomerados basáticos, cuja coloração escura deve-se à presença de minerais máficos tais quais piroxênios e anfibolitos. Essa unidade ocupa 25 \% da ilha de Santa Bárbara, 18,1 \% de Sueste e 23,3 \% de Siriba.

PRAIA (PR) - Unidade representativa das praias atuais formadas por areia de origem predominantemente conchífera e algal, com presença em menor quantidade de minerais máficos provenientes do basalto. A análise de raios $\mathrm{X}$ mostra a presença marcante de calcita magnesiana (Ca,Mg) $\mathrm{CO}_{3}$ ), com picos em 2,99 $\AA$; 3,78 $\AA$; 2,45 $\AA$; 2,26 , quartzo

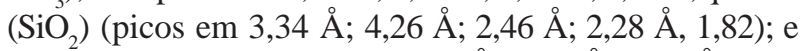

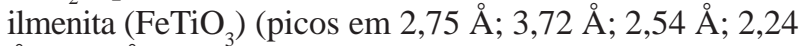
$\AA ;$;,73 $\AA$ ). Na ilha de Santa Bárbara, ocorre desde a Enseada do Portinho até próximo a Caverna do Siriba e em toda a porção central da costa norte, ocupando cerca de $17 \%$ da ilha. Na ilha Redonda, essa unidade representa 8,3 \% da área total.

NEOSSOLO LITÓLICO Húmico fragmentário ornitogênico (RLh e RLh1) - Unidade composta por solos rasos, com o horizonte A rico em carbono orgânico repousando diretamente sobre a rocha fragmentária. A unidade RLh ocupa a porção mais elevada da ilha de Santa Bárbara, compreendendo 13,1 \%, sob forte influência de ninhal atual de atobás, sendo representada pelo perfil 6. Os teores de P e $\mathrm{Ca}^{2+}$, no horizonte A, estão entre os mais elevados de todos os solos analisados no presente estudo (Tabela 2). Já a unidade RLh1 ocorre nos topos mais aplainados da ilha Siriba, que caem em declives suaves na direção norte, ocupando 34,4\% da ilha. É representada pelo perfil 7, em área sem atividade atual de aves, apresentando valores baixos de $\mathrm{Pe}$ Ca, quando comparado ao perfil 6 e à maioria dos demais solos analisados, com exceção dos perfis 2 e 5 (Tabela 2).

NEOSSOLO LITÓLICO Distrófico fragmentário ornitogênico (RLd, RLd1, RLd2) - São solos rasos, com horizonte A diretamente sobre o substrato rochoso fragmentado. A unidade RLd apresenta evidências de erosão laminar severa, com remoção parcial do horizonte A, estando restrita à ilha Santa Bárbara, onde ocupa 12,5 \% da área mapeada. Já a unidade RLd1 representa uma fase escarpada, que marca transição abrupta entre a porção central das ilhas e as praias, ocorrendo em todas as ilhas, exceto em Redonda. Em Santa Bárbara, RLd1 ocorre predominantemente no extremo oeste e na porção centro-norte da ilha, representando 14,5\% da área total. Em Sueste, ocorre nas escarpas da face sul, formando bolsões de solo nas porções mais estáveis do terreno em meio a blocos de basalto, representando 27,3\% da ilha. Em Siriba, essas escarpas ocupam toda a porção sul e sudoeste da ilha, representando 16,1 \% do ambiente emerso mapeado. A unidade RLd2 é restrita a ilha de Santa Bárbara, ocupando a sua porção central e representando cerca de 7,6 \% da ilha. Constitui uma fase em rampas e topos erodidos, com elevada pedregosidade em superfície, sob vegetação de escrube baixo.

NEOSSOLO REGOLÍTICO Eutro-úmbrico ornitogênico (RReh) - São solos restritos ao ambiente de pós-praia, onde as areias carbonáticas derivadas de sedimentos marinhos rasos, retrabalhados pelo mar e pelos ventos, formam pequenas feições eólicas que sobem as encostas mais suaves dos platôs basálticos, constituindo substrato para a pedogênese. São solos arenosos, ricos em areia carbonática e minerais máficos. Correspondem a antigos terraços marinhos, ocupando cerca de $12,5 \%$ da área da ilha Redonda e 4,6 \% de Santa Bárbara. O perfil 1, representativo dessa unidade, apresenta valores elevados de $\mathrm{pH}, \mathrm{Ca}^{2+}{\mathrm{e} \mathrm{Mg}^{2+} \mathrm{em}}^{2}$ relação aos demais solos estudados e 100 \% de saturação de bases (V\%) (Tabela 2).

CAMBISSOLO HÚMICO Distrófico ornitogênico fase relevo escarpado e erodido (CHd) - São solos com horizonte B incipiente. A maior profundidade efetiva permite maior retenção de água em relação aos demais solos de Abrolhos, permitindo vegetação de maior porte. O perfil 5, representativo dessa unidade, é um solo profundo $(>120 \mathrm{~cm}) \mathrm{com}$ base nos critérios de profundidade do SBCS (EMBRAPA, 2006), desenvolvido sobre o saprolito do basalto. Os teores de P são elevados a partir do horizonte Bi (1544,3 mg.dm ${ }^{-3}$ ), mantendo-se altos mesmo no horizonte C (1304,9 mg. $\left.\mathrm{dm}^{-3}\right)$. Em Santa Bárbara, a unidade CHd ocorre nas encostas escarpadas norte e sul da porção centro-oeste da ilha de Santa Bárbara, ocupando 7,3 \% da ilha. Na ilha Redonda, ocupa as escarpas que delimitam a costa leste e sudeste, representando cerca de 10,2 \% da ilha.

CHERNOSSOLO RÊNDZICO Lítico fragmentário ornitogênico (MDi) - São solos que apresentam acumulação de húmus, em profundidades de até $40 \mathrm{~cm}$, repousando sobre materiais carbonáticos. Estão restritos à ilha Santa Bárbara, ocupando cerca de 3,1 \% da área emersa. Não foram coletados solos representativos dessa unidade.

CHERNOSSOLO EBÂNICO Lítico ornitogênico + CAMBISSOLO HÚMICO Epi-eutrófico ornitogênico (MEk) - Essa unidade ocorre nas encostas da face sul e oeste, bem como nos topos aplainados de Sueste, representando cerca de 54,5 \% da ilha. É composta por uma associação de solos ricos em carbono orgânico, com elevados valores de $\mathrm{P}$ e $\mathrm{Ca}^{2+}$. O Chernossolo representado pelo perfil 9 apresenta teores elevados de $\mathrm{Ca}^{2+}$ em relação a todos os solos estudados no presente trabalho. O caráter ebânico refere-se à coloração escura resultante do elevado teor de carbono 


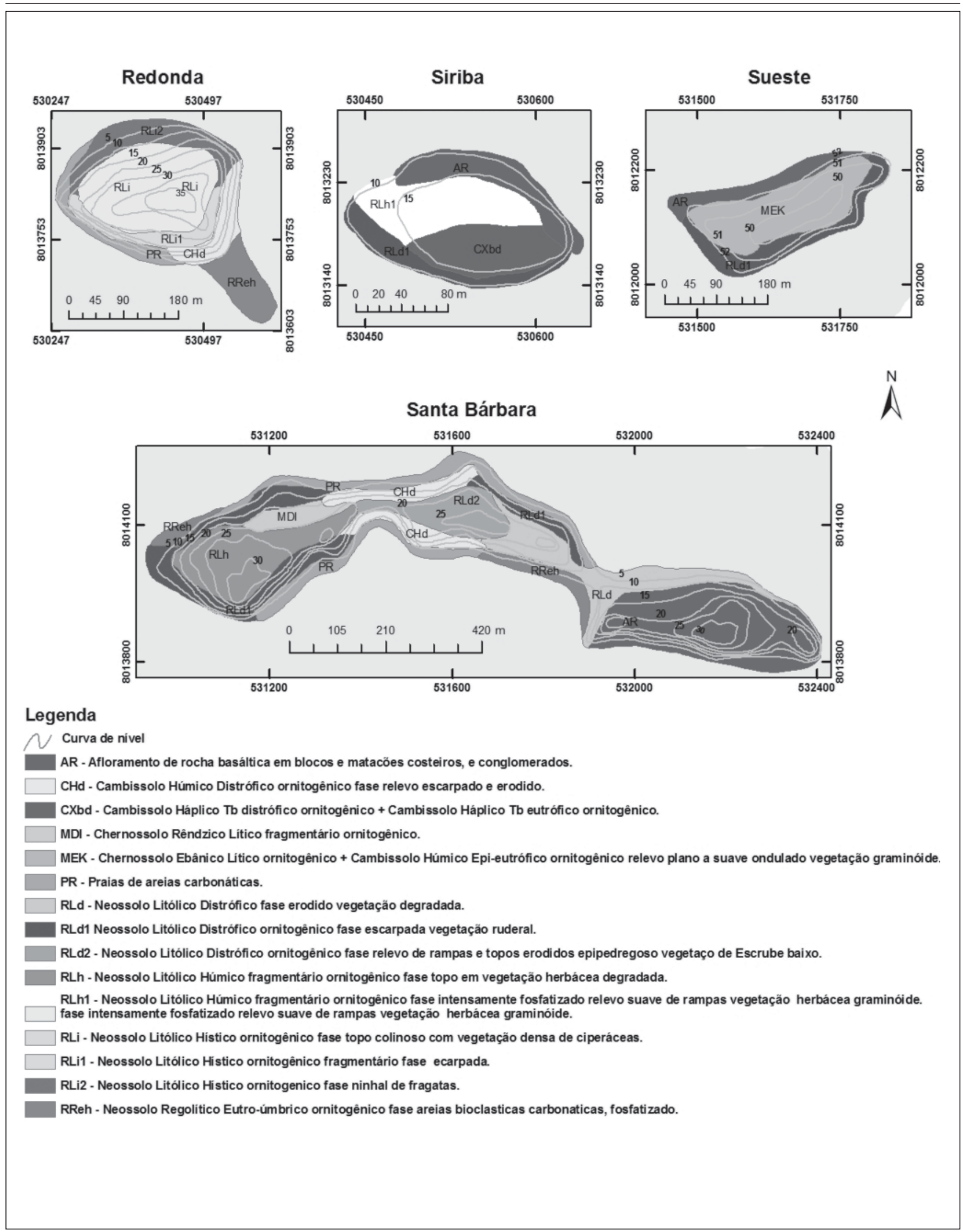

Figura 2 - Distribuição das unidades de mapeamento de solos identificadas no arquipélago de Abrolhos. 
orgânico. Situado no terço superior da encosta, o solo é raso, com horizonte A diretamente sobre a rocha, caracterizando um contato lítico. Já o perfil 10 apresenta saturação de bases (V) menor que 65 \% não podendo ser classificado como Chernossolo. Contudo os altos teores de $\mathrm{Ca}^{2+}$, COT, e a coloração escura assemelham esse solo ao perfil 9. Ambos apresentam altos teores de P extraível, indicando a influência das aves na formação do solo. Dentro dessa unidade, ocorrem, ainda, inclusões de ORGANOSSOLO HÁPLICO Sáprico ornitogênico, representado pelo perfil 8. É um solo com elevados teores de COT até mesmo no horizonte $\mathrm{C} / \mathrm{R}$. Os teores de $\mathrm{P}$ são relativamente baixos no horizonte $\mathrm{O}$, quando comparados aos demais solos analisados, aumentando em profundidade (Tabela 2).

CAMBISSOLO HÁPLICO Tb distrófico ornitogênico + CAMBISSOLO HAPLICO Tb eutrófico ornitogênico (CXbd) - Essa unidade é restrita à face sul de Siriba, representando cerca de 26,1 \% da ilha. Ocorre próxima dos ninhais atuais de Atobás. São solos fortemente fosfatizados, semelhantes ao perfil 5 descrito em Santa Bárbara. Contudo, em Siriba, ocorrem níveis de conchas carbonáticas, o que sugere a ocorrência de solos eutróficos.

NEOSSOLO LITÓLICO Hístico (RLi, RLi1 e RLi2) - São solos rasos com horizonte orgânico com menos de $20 \mathrm{~cm}$ de espessura assentado diretamente sobre a rocha, estando restritos a ilha Redonda. A unidade RLi ocupa cerca de 41 \% da área total, na porção central mais elevada da ilha. É representada pelo perfil 2, que apresenta horizontes superficiais com teores de carbono orgânico variando de 93,7 a 113,9 g. $\mathrm{kg}^{-1}$ com predomínio de material pouco humificado (fíbrico). Os valores de $\mathrm{pH}$ variam de 3,8 a 3,2, sendo os menores entre todos os solos estudados no presente trabalho (Tabela 2). O alto teor de matéria orgânica explica os valores elevados de $\mathrm{H}+\mathrm{Al}$, resultando em CTC total (T) igualmente elevada. Essa característica, aliada aos baixos teores de bases trocáveis, caracteriza um solo distrófico, com saturação de bases (V) variando de 7,4 a 6,1 \%. Os valores de P extraível são baixos em relação aos demais solos estudados.

Nas porções mais íngremes, têm-se fases erodidas desse solo, com o horizonte hístico formando bolsões em meio aos blocos basálticos, caracterizando a unidade RLi1 (Figura 2). Nas áreas mais rebaixadas de terraço marinho e rampa, na porção norte da ilha, tem-se a segunda maior unidade mapeada (RLi2), ocupando 17,9 \% da ilha, sendo representada pelo perfil 3. O solo é raso, composto por horizonte hístico com teores de carbono orgânico variando de 84,2 a 91,2 g. kg-1 (Tabela 2). Comparado ao perfil 2, os valores de $\mathrm{Ca}^{2+}$ são extremamente elevados, porém a saturação de bases (V) permanece inferior a $50 \%$ (Tabela 2), caracterizando um solo distrófico. No entanto, é um solo de melhor status nutricional do que o perfil 2. Os valores de P extraível com Melich-1 estão entre os mais elevados de todo o arquipélago, ultrapassando 3.950 mg. $\mathrm{kg}^{-1}$ de P.

\section{Solos submersos}

Ocorrem em estuários a profundidades rasas (geralmente $<5 \mathrm{~m}$ ), em angras protegidas, baías e nas partes a montante das barreiras de lagunas litorais (Demas \& Rabenhorst, 2001). Após sofrerem a atuação dos processos pedogenéticos, os substratos estuarinos são transformados em solos. Tais processos incluem adições biogênicas de $\mathrm{CaCO}_{3}$ e húmus da biota bentônica, bioturbação de moluscos e minhocas e transformação química do enxofre passando pelo processo de sulfidização (piritização); todos contribuindo para transformar sedimentos superficiais em horizontes do solo. No Brasil, não existem estudos sobre tais solos, apesar da enorme riqueza de ambientes estuarinos, além de pantanais, ilhas, etc. No Arquipélago de Abrolhos, solos submersos foram identificados preliminarmente ao redor de todas as ilhas, sendo mapeadas 2 unidades, somando aproximadamente 322 ha, assim descritos:

(1) Solos submersos de areias carbonáticas com cobertura herbacea e algal (SS1) - ocorrem em plataformas rasas mais distantes em relação às ilhas, sem influência de detritos basálticos.

(2) Solos submersos com fragmentos (blocos e matacões) de basalto com cobertura algal (SS2) - ocorrem na porção mais próxima das ilhas, sendo influenciados pela deposição de fragmentos de basalto.

\section{Discussão}

Todos os solos estudados em Abrolhos apresentam maior ou menor grau de ornitogênese. Em certos casos isto é evidente devido à existência de ninhais atuais. Contudo, em outros casos, são as características químicas do solo que indicam antigas áreas de nidificação, atualmente inexistentes. Simas et al (2007) propuseram a inclusão do caráter ornitogênico para solos da Antártica com valores maiores que 500 mg. $\mathrm{kg}^{-1}$ de P extraível com Melich-1, em sítios claramente influenciados por aves. Estudos recentes vêem demonstrando a ampla ocorrência de solos afetados por aves em regiões tropicais (Oliveira, 2008; Clemente et al., 2009). No entanto, o atual sistema brasileiro de classificação de solos (EMBRAPA, 2006) não contempla o caráter ornitogênico, dificultando a classificação desses solos.

A comparação entre os perfis 2 e 3 evidencia, de forma didática, o efeito da ornitogênese nas características químicas dos solos ao longo do tempo. O perfil 3 encontra-se sob influência atual de ninhal de Fragatas, resultando em teores muito elevados de $\mathrm{P}$ extraível em superfície, bem como elevados valores de $\mathrm{Ca}^{2+}$. Isto se deve à proximidade desse perfil em relação a colônias ativas de atobás, que constituem fonte de fases primárias de minerais de $\mathrm{P}$ e Ca (ex. apatita de osso, carbonato de cálcio biogênico). Contudo a reação ácida em todos os horizontes favorece a dissolução desses fosfatos primários e a neoformação de fases de P-Al e P-Fe. Por sua vez, o perfil 2 apresenta-se mais ácido, com teores reduzidos de $\mathrm{Ca}^{2+}$ e $\mathrm{P}$. 
Carlos Ernesto Gonçalves Reynaud Schaefer et al.

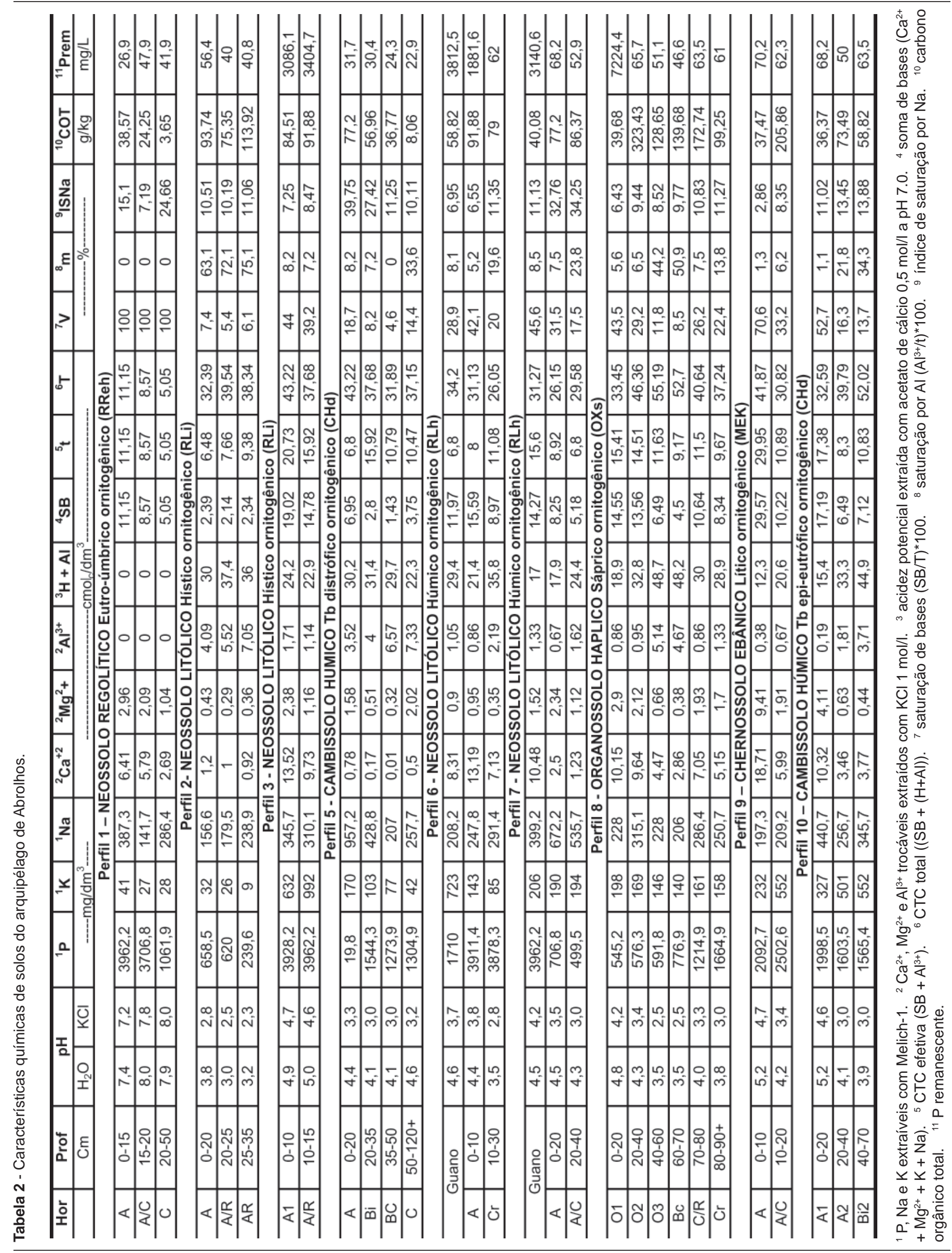


Esse dado indica uma influência por aves menos intensa ou, ainda, a ausência de atividade por um período suficientemente longo para remoção do P depositado, seja pela absorção pela vegetação ou remoção via dissolução e lixiviação das formas de $\mathrm{P}$, ou ambos. Os baixos valores de $\mathrm{Ca}^{2+}$ em relação ao perfil 3 corroboram a hipótese de uma menor atividade de aves, sem deposição de conchas carbonáticas típicas das áreas com ninhais ativos ou que foram mais intensamente ornitogênicas. Mesmo assim, a redução dos valores de P em profundidade evidencia que houve aporte desse nutriente na superfície. $\mathrm{O}$ baixo $\mathrm{pH}$, os baixos teores de $\mathrm{Ca}^{2+}$ e altos teores de $\mathrm{Al}^{3+}$ denotam um pedoambiente favorável à formação de fosfatos de alumínio (Simas et al., 2007).

O processo de fosfatização tem início com a deposição de guano em superfície, resultando em valores de $\mathrm{pH}$ e $\mathrm{Ca}^{2+}$ elevados, dadas a reação alcalina do guano e a presença de minerais de P-Ca (Tatur et al., 1997; Simas et al., 2007). A decomposição microbiana do guano resulta na produção de ácidos sulfúrico e nítrico, que aceleram o intemperismo do substrato e a formação de minerais de P-Al e P-Fe (Tatur et al., 1997). Estudos sobre fosfatização no arquipélago de Fernando de Noronha (Oliveira, 2008) mostram que, uma vez cessada a deposição de guano fresco, a acidificação do solo promove a dissolução de fosfatos de cálcio, possibilitando a reação com o alumínio proveniente do saprolito, com formação de fases amorfas e cristalinas de P-Al.

Todos os solos da parte superior das ilhas Siriba e Redonda (perfis 2, 3 e 7) são ornitogênicos em maior ou menor grau. Ao longo da evolução da paisagem, houve remoção de $\mathrm{P}$ nos horizontes superficiais, seja pela erosão ou pela absorção pela vegetação, com acúmulo em profundidade de formas mais estáveis de $\mathrm{P}$.

\section{Conclusões}

No arquipélago de Abrolhos, a presença generalizada de solos ornitogênicos em áreas sem nidificação atual ou com fraca nidificação, indica uma ocupação por aves bem mais ampla no passado. Tal fato pode ser verificado pelos elevados teores de P e Ca em solos ricos em matéria orgânica humificada.

Apesar da pequena dimensão da ilha Sueste, os solos nela formados estão entre os mais profundos do arquipélago de Abrolhos, sendo ainda os mais intensamente fosfatizados e ricos em matéria orgânica humificada, apesar da pobreza atual da vegetação herbácea da ilha e da menor colonização relativa atual de aves, que se encontram em ninhais dispersos. Esses dados corroboram com uma maior atividade pretérita de aves no arquipélago.

O reflexo da ação de aves nas características químicas e morfológicas dos solos é marcante no arquipélago, semelhantemente ao observado em outras ilhas oceânicas brasileiras ou, mesmo, em ilhas antárticas. Tal fato reforça a necessidade de se definir o caráter ornitogênico no sistema brasileiro de classificação de solos para uma classificação mais adequada desses solos, em função da grande importância ecológica que desempenham nos ecossistemas terrestres e insulares.

\section{Referências bibliográficas}

BRASIL. Plano de Manejo do Parque Nacional Marinho dos Abrolhos. Instituto Brasileiro do Meio Ambiente e dos Recursos Naturais e Renováveis/Fundação Pró-Natureza, 1991. 96 p.

BRINDLEY, G.W., BROWN, G. Crystal structures of clay minerals and their $X$ ray identification. Monograph 5. London: Mineralogical Society, 1980.

CLEMENTE, E. P., SCHAEFER, C.E.G.R., OLIVEIRA, F.S., ALBUQUERQUE-FILHO, M.R., ALVES, R.V., SÁ, M.M.F., MELO, V.F, CORREA, G.R. Topossequência de solos na ilha da Trindade, Atlântico Sul. R. Bras. Ci. Solo v. 33, n. 5, p. 1357-1372, 2009.

DEMAS, G.P., RABENHORST, M.C. Factors of subaqueous soil formation: a system of quantitative pedology for submersed environments. Geoderma, v. 102, p. 189-204, 2001.

EMBRAPA - Centro Nacional de Pesquisa de Solos. Sistema brasileiro de classificação de solos. (2 ed.). Brasília: EMBRAPSSPI, 2006. 420 p.

EMBRAPA - Centro Nacional de Pesquisa de Solos. Manual de métodos de análise de solo. Rio de Janeiro: Centro Nacional de Pesquisa de Solos, 1997. 212p.

MELFI, A. J., FLICOTEAUX, R. Les coûtes phosphatées des basaltes de l'Archipel d'Abrolhos (Bahia, Brésil): des roches formées au quaternaire récent à partir de guanos. Comptés Rendus de L'Académie des Sciences Serie II - Fascicule, v.330, p. 193200, 2000.

KEMENES, A. Distribuição espacial das plantas terrestres no Parque Nacional Marinho de Abrolhos. Revista Brasileira de Botânica, São Paulo, v. 26, p. 141-150, 2003.

JENNY, H. Factors of soil formation: a system of quantitative pedology. New York: McGraw-Hill, 1941. 281 p.

OLIVEIRA, F.S. Fosfatização de rochas e solos nas Ilhas Oceânicas Brasileiras. Viçosa: UFV - Departamento de Solos, 2008. (Tese de Mestrado).

LEMOS, R.C., SANTOS, R.D. Manual de descrição e coleta de solo no campo. (4. ed.) Viçosa: SBCS, 2005. 84p.

SIMAS, F.N.B., SCHAEFER, C.E.G.R., MELO, V.F. DE, ALBUQUERQUE-FILHO, M.R., MICHEL, R.F, PEREIRA, V.V., GOMES, M.R.M. Ornithogenic Cryosols from Maritime Antarctica: phosphatization as a soil forming process. Geoderma, v.138, p.191-203, 2007.

SCHAEFER, C.E.G.R., PEREIRA, T.L., DERGAM, J.A., ALBUQUERQUE, M.A. SOUZA, E. Barreira biogeográfica da Península de Abrolhos: Geomorfologia, ictiofaunda e conciliação de dados botânicos. In: Ilhas oceânicas brasileiras: da pesquisa ao manejo. Brasília: Ministério do Meio Ambiente, 2006. p. 235-245.

SCHAEFER, C.E.G.R, SIMAS, F.N.B., GILKES, R.J., MATHISON, C., COSTA, L.M. Micromorphology and microchemistry of Cryosols from Maritime Antarctica. Geoderma, v. 144, p.104115, 2008.

TATUR, A., MYRCHA, A., NIEGODZISZ, J. Formation of abandoned penguin rookery ecosystems in the maritime Antarctic. Polar Biol., v. 17, p.405-417, 1997.

Artigo recebido em 20/10/2009 e aprovado em 16/07/2010. 